\title{
(6) OPEN ACCESS \\ Anatomical basis and histopathological changes resulting from selective internal radiotherapy for liver metastases
}

\author{
Lai Mun Wang, ${ }^{1}$ Anant R Jani, ${ }^{2}$ Esme J Hill, ${ }^{2}$ Ricky A Sharma ${ }^{2}$
}

${ }^{1}$ Department of Cellular Pathology, Oxford University Hospitals NHS Trust, John Raddliffe Hospital, Oxford, UK ${ }^{2}$ Department of Oncology, Cancer Research UK-Medical Research Council Gray Institute, University of Oxford, Oxford, UK

\section{Correspondence to} Dr Ricky Sharma, Oncology Department, Cancer Research UK-Medical Research Council Gray Institute, University of Oxford, Old Road Campus Research Building, Oxford OX3 7DQ, UK;

ricky.sharma@oncology.ox.ac.uk

Received 21 September 2012 Revised 5 October 2012 Accepted 9 October 2012 Published Online First 16 November 2012

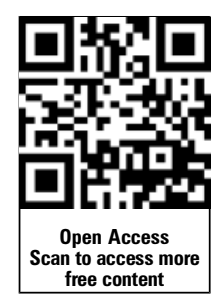

To cite: Wang $L M$, Jani $A R$, Hill EJ, et al. J Clin Pathol 2013;66:205-211.

\begin{abstract}
Background Knowledge that liver tumours preferentially take their blood supply from the arterial blood supply rather than the portal venous system can be used for local delivery of treatment or for embolisation to cut off the blood supply to tumours. Aims To present histological evaluation of malignant and non-malignant hepatic tissue of one such therapy, selective internal radiation therapy (SIRT) with yttrium-90 microspheres, to decipher its principal mechanism of action.

Methods The H\&E stained sections of hepatic resection specimens from three patients with liver metastases from colorectal (CRC) cancer, who underwent hepatic surgery 4-9 months following SIRT, were examined and the pathological changes documented.

Results Resin microspheres were identified in the vascular tumour bed and vessels within the portal tracts of the background liver parenchyma. Microspheres were usually associated with giant cell reaction or histiocytes. In the tumour bed, tumour necrosis, mucinous alteration, collections of foamy histiocytes, ectatic vessels, calcification and fibrosis were observed. There was minimal cellular inflammatory response observed, suggestive of direct radiation injury as a non-immune mediated process.

Conclusions We describe in detail the spectrum of histopathological changes in malignant tissue and liver parenchyma in patients with metastatic CRC treated with SIRT. Our findings are consistent with the hypothesis that the principal mechanism of action of SIRT appears to be via arterially directed delivery of highly radioactive microspheres in and around the vascular tumour bed rather than by micro-arterial embolisation.
\end{abstract}

\section{INTRODUCTION}

Therapies directed specifically into the arterial blood supply of the liver, such as hepatic arterial infusional chemotherapy, trans-arterial chemo-embolisation (TACE) and radioembolisation, are today used as anatomically selective treatments to treat inoperable malignancies or to downstage primary and secondary liver cancers to respectability. ${ }^{1-3}$ The scientific basis for the first postulation that locally directed therapies could be selectively delivered to malignancies via the arterial blood supply of the liver is an example from medical history of how meticulous anatomical and pathological observation can eventually impact on the treatment of patients with cancer. In this report, we describe the historical background to anatomically targeted liver therapies and histological changes associated with the most recently developed form of this therapy, selective internal radiation therapy (SIRT).

In 1774, Herman Boerhaave first described the dual blood supply to the liver from the hepatic artery and the portal vein. ${ }^{4}$ In the 19th century, it was discovered that the portal vein supplied most of the liver's nutrients and this knowledge led anatomists to assume that the portal vein was also primarily responsible for supplying blood and nutrients to malignancies of the liver. ${ }^{5}$ Indeed, the turning point in our understanding of the blood supply to liver tumours, and how they might potentially be selectively targeted by virtue of their blood supply, came about in 1937 when R Douglas Wright published a seminal study in the Journal of Pathology and Bacteriology. ${ }^{6}$

Prior to Wright's work, it was generally accepted that the majority of metastatic carcinomas metastasise to the liver via the portal vein and therefore derive their blood supply from the same vessels. ${ }^{5}$ In his landmark paper, Wright's key observation was the identification of vessel structures in the stroma of liver carcinomas, which corresponded more closely to arteries and arterioles than to normal vessels in the venous system. ${ }^{6}$ He thus postulated that carcinomas derived their blood supply from the arterial system. To provide evidence in support of this hypothesis, he developed a novel method to determine the source of the blood supply to liver carcinomas. Livers were resected from human cadavers with hepatic arteries and portal veins intact and the vessels were subsequently perfused and washed with saline. Red gelatine masses were then injected into the portal vein while blue gelatine masses were injected into the hepatic artery at much higher pressures, followed by sectioning the next day (figure 1). Using this method, Wright was able to clearly demonstrate that:

When a fibrovascular stroma develops in secondary carcinomata in the liver, the afferent blood supply to these vessels is from the hepatic artery. ${ }^{6}$

Following up Wright's observations, Breedis and Young $^{7}$ suggested the concept of arterially directed therapy to selectively target the blood supply of malignancy and posed the following research question to the next generation of researchers:

Would ligation of the hepatic artery cause regression of hepatic neoplasms by cutting off their blood supply?

From the 1950s onwards, various drugs were used for intra-arterial hepatic chemotherapy, 


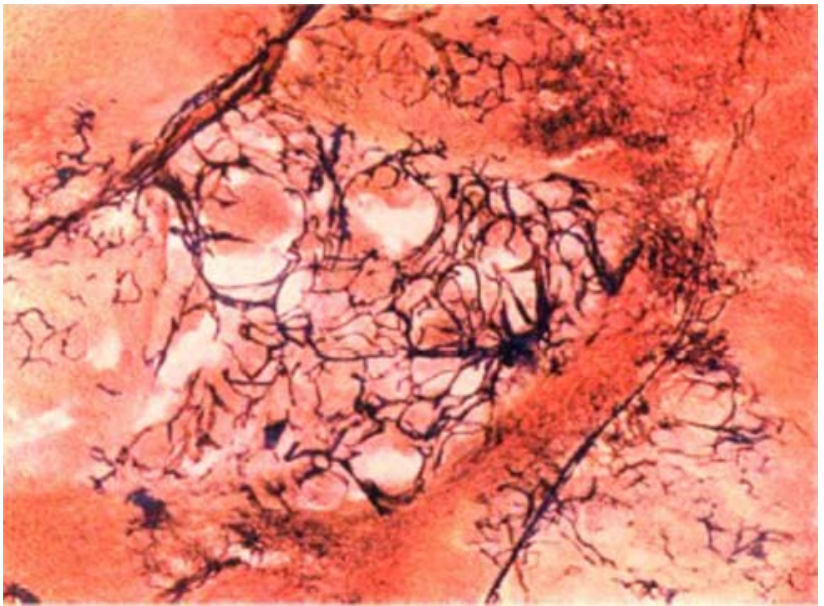

Figure 1 Colour photomicrograph of a liver metastasis. R Douglas Wright developed a way of injecting blue gelatine via the hepatic artery and red gelatine via the portal vein to demonstrate the junction of hepatic artery capillaries and portal venules. ${ }^{6}$ Reproduced with permission from the Journal of Pathology and Bacteriology.

demonstrating regression of primary or secondary malignancies in some cases. ${ }^{8} 9$ In parallel, other clinical researchers developed ways of cutting off the arterial blood supply to tumours, such as trans-arterial embolisation. ${ }^{10}$ The development of modern interventional radiology from the 1980 s onwards permitted arterial approaches to therapy to be performed in a minimally invasive way. An oily contrast medium, lipiodol, was mixed with chemotherapeutic drugs as the basis for TACE in the 1980s. ${ }^{11}$ Various forms of TACE are now considered routine therapy for primary liver cancer.

The most recent development in arterially directed liver therapy is SIRT using radioactive microspheres. It is a technique that has been developed to target multiple sites of disease within the liver as a form of arterially delivered brachytherapy. ${ }^{3}$ TheraSpheres (MDS Nordion, Kanata, Ontario, Canada) are glass microspheres, and SIR-Spheres (Sirtex Medical, Sydney, Australia) are resin microspheres, both of which contain the $\beta$-emitter, yttrium-90, and have a mean diameter of 20-35 $\mu \mathrm{m}$. The technique of SIRT involves an outpatient procedure in which trans-femoral catheterisation is performed and microspheres are injected into the arterial supply of liver malignancies under fluoroscopic guidance. SIRT is currently offered as a treatment option to patients with inoperable primary or secondary liver malignancies, and is being tested in randomised, multicentre clinical trials in combination with first-line systemic chemotherapy. $^{3} 12$

There is current debate regarding the principal mechanism of action of SIRT in treating cancer. ${ }^{13-15}$ Does it act primarily via arterially directed delivery of high dose radiotherapy in and around the vascular tumour bed, or by micro-arterial embolisation, cutting off the blood supply to malignancies similar to the mechanism described by Breedis and Young? Although large case series of patients having surgery after SIRT are difficult to obtain since SIRT is not used to treat patients with resectable disease, that is, only patients downsized from inoperable disease are considered for subsequent liver surgery, we describe three clinical cases in detail to help to inform the current debate.

\section{METHODS}

We reviewed the case notes of 24 patients treated with SIRT at the Oxford University Hospitals NHS Trust between April 2010 and April 2012 in order to identify three patients with metastatic colorectal cancer (CRC) who were downsized from inoperable disease by SIRT to have hepatectomy or liver segmentectomy.

\section{Case 1}

This patient initially presented acutely with colonic obstruction due to a stenosing proximal sigmoid colon cancer, for which the patient underwent a Hartmann's resection. Postoperative histopathological assessment revealed a moderately differentiated adenocarcinoma, pT4bN2, with extramural vascular invasion and margin-negative resection. On MRI scan, synchronous multiple bilobar hepatic metastases were documented. The patient received one cycle of systemic chemotherapy with oxaliplatin and flurorouracil, but developed coronary vasospasm and further chemotherapy was contraindicated. She received SIRT 17 days later at a dose of $0.4 \mathrm{GBq}$ to the right side of the liver and $0.5 \mathrm{GBq}$ to the left side. Six weeks later, the patient commenced six cycles of irinotecan chemotherapy and cetuximab therapy. Two months from the last dose of chemotherapy, she underwent a left hepatectomy with segment VI resection. The patient developed postoperative chest infection, which required intravenous antibiotic treatment for full recovery, but there were no other postoperative complications.

\section{Case 2}

This patient presented with rectal bleeding and was discovered to have a moderately differentiated rectosigmoid adenocarcinoma (T3 N2 on pelvic MRI) and two synchronous liver metastases (in segments 7 and 8 on liver MRI). She received systemic chemotherapy with oxaliplatin and fluorouracil. SIRT was delivered 15 days after commencement of chemotherapy $(0.5 \mathrm{GBq}$ to the right side of the liver) in order to treat the metastatic disease evident on scans and to cause compensatory hypertrophy of the left lobe of the liver. She received six cycles of chemotherapy over 3 months and underwent a right hepatectomy and cholecystectomy 6 weeks after her last dose of chemotherapy. There were no postoperative complications. Three months later, the patient had a laparoscopic anterior resection to remove the primary tumour. Pathology showed pT3N1 moderately differentiated adenocarcinoma, no extramural vascular space invasion was identified and resection margins were negative.

\section{Case 3}

This patient presented with right upper quadrant pain, 5 years after she had had a moderately differentiated adenocarcinoma of the rectum removed by anterior resection. The final pathology stage was pT3N0, and extramural vascular invasion was seen. The resection margins were negative. MRI of the liver confirmed extensive metastases involving the right lobe of the liver and segment IV. Initially, the patient received six cycles of oxaliplatin and fluororouracil chemotherapy over 3 months, which resulted in a partial response and decreased fluorodeoxyglucose (FDG) uptake in the liver metastases on positron emission tomography (PET)-CT, but the disease remained inoperable. One month later, the patient received SIRT (1.0 GBq to the right side of the liver) with two cycles of concomitant oxaliplatin and fluorouracil chemotherapy followed by further two cycles of fluorouracil alone (oxaliplatin omitted because of peripheral neuropathy). SIRT resulted in a $25 \%$ increase in the volume of the left lobe of the liver (not treated with microspheres) and the metastatic disease became technically resectable on the subsequent scans at 3 months and 6 months. The patient underwent a right hemihepatectomy 
9 months after SIRT. No complications were recorded within 30 days of liver surgery.

The H\&E slides of sections taken from the resected liver specimens of these three patients were examined. The volume of residual viable tumour cells (total amount present in all sections taken of each tumour deposit) and histopathological features in tumour and non-tumour liver tissue were recorded.

\section{RESULTS}

We examined the histopathological changes in five metastatic CRC tumour deposits in three patients who underwent liver surgery after SIRT. The time between SIRT and surgery in our series ranged from 4 to 9 months. Three tumour deposits from all three patients showed good partial pathological response. One of the two deposits of case 2 exhibited complete pathological response while the second deposit of case 1 demonstrated minimal response.

Microspheres were identified in the vascular tumour bed as well as in vessels within the portal tracts of the background liver parenchyma. The characteristic microspheres were usually associated with giant cell reaction or histiocytes (figure 2). Consistent with this timescale, we observed radiation effects which were subacute and delayed/chronic. The spectrum of changes observed in individual tumour deposits are illustrated and described in detail in the legends to figure 3 (case 1), figures 4 and 5 (case 2) and figure 6 (case 3). In summary, within the tumour bed, foci of stromal fibrinous exudate typical of delayed radiation injury, composed of delicate collagen and fibroblasts, were present in all three patients but was least appreciable in the lesion showing the least response (case 1). Other treatment effects included tumour necrosis, mucinous alteration, aggregates of foamy histiocytes, calcification and fibrosis. In general, there was minimal cellular inflammatory response; this observation is supportive of direct radiation injury as a non-immune mediated process. ${ }^{16}$

In the background non-tumour liver parenchyma, tumour mass effect-related changes, such as sinusoidal dilatation and bile ductular reaction, were noted in the immediate vicinity of the tumour. Severe background liver steatosis was observed in one patient (case 3), which may be related to the use of oxaliplatin-

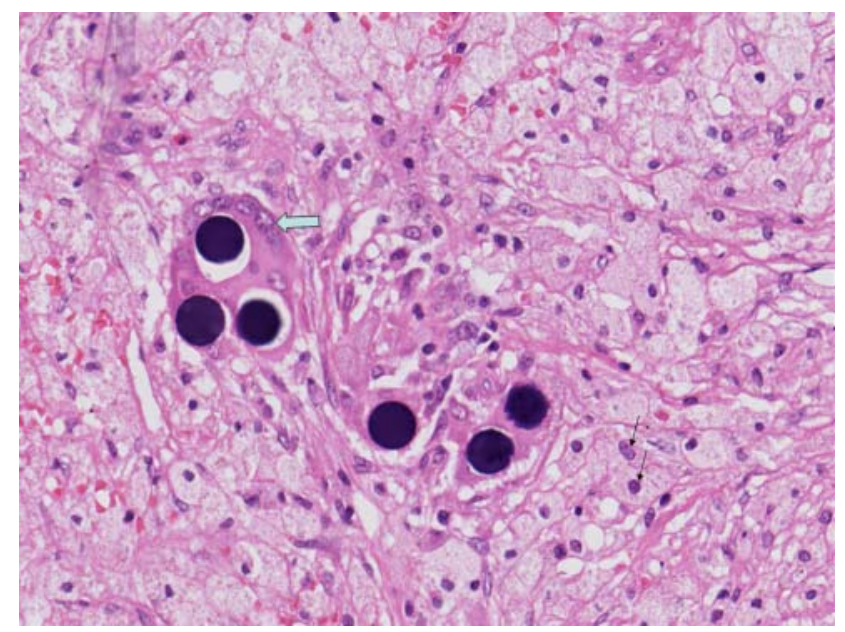

Figure $2 \mathrm{H} \& \mathrm{E}$ section of liver tissue in patient with metastatic colorectal cancer 4 months after selective internal radiation therapy (200x). Shows characteristic microspheres in association with giant cell reaction (block arrow). Surrounding 'sea' of foamy histiocytes (fine arrows) is also seen. based combination chemotherapy in addition to $\mathrm{SIRT}^{17}$ One patient (case 2) had features of veno-occlusive disease (VOD) and although this has been described in hepatic radiation injury, it may also be attributed to oxaliplatin-based combination chemotherapy in this case. ${ }^{17}$ It should be noted that no severe bridging fibrosis was observed in any of the cases studied.

\section{DISCUSSION}

The historical evolution of arterially-directed therapies for primary and secondary malignancies of the liver demonstrates that meticulous observation may lead to the development of effective new ways of treating cancer. Wright's pioneering work led from the courage of an individual to question commonly held beliefs of the time. Breedis and Young generated hypotheses which led to the development of arterially directed therapies.

The advent of modern diagnostic radiology several decades after Breedis and Young's paper has confirmed that primary and secondary malignancies of the liver preferentially take their blood supply from the arterial system rather than the portal venous system. Preclinical and clinical evidence in support of this hypothesis has been reported from a variety of model systems. ${ }^{78}$ Of particular note is a research study reported in the American Journal of Pathology, the same journal in which Breedis and Young's paper appeared, 55 years earlier. ${ }^{19}$ In this study, researchers experimentally induced liver tumours in mice and applied vascular corrosion casting to show that, after a tumour grows to $2.0-2.5 \mathrm{~mm}$ in diameter, its arterialisation is inevitable. ${ }^{19}$ Importantly, this study described at the sub-mm level the architectural changes in the liver by which malignancy can co-opt the host arterial vasculature.

In patients with cancer, the application of ultrasound angiography in patients with liver tumours has demonstrated that established malignancy can take its blood supply from the portal venous system as well as the arterial system, but that the arterial blood supply to a malignancy appears to determine its growth rate. ${ }^{20}$ Investigators studied a group of patients with well differentiated hepatocellular carcinomas, in whom they found that tumours that had a faster rate of progression had a predominantly arterial blood supply. ${ }^{20}$ The importance of arterial blood supply in preference to portal venous blood has been corroborated by another clinical study that used a different imaging modality, perfusion $\mathrm{CT}^{21}$

The most recent development in arterially directed therapy of primary and secondary liver cancer is SIRT and the histopathological changes observed following SIRT treatment of the liver have not been reported in detail. Our paper is the first to describe in detail the spectrum of histopathological changes in CRC liver metastases after SIRT therapy (table 1).

In a study by Whitney et al, the investigators have briefly described the histology in four patients with metastatic disease to the liver from different primary sites who underwent hepatic resection. ${ }^{15}$ Their emphasis was predominantly on the percentage of tumour necrosis, which ranged from $45 \%$ to $80 \%$, but the authors did also note moderate to severe hepatic inflammation and fibrosis. Specific details describing the 'hepatic inflammation' referred to were not included in the paper. In a case report by Hadaki et al, the clinical team describe a patient with two synchronous colonic liver metastases. ${ }^{22}$ The post-SIRT resected specimen showed complete pathological response in the two tumour deposits. Fibrosis and a small amount of extracellular mucin was identified. This case report is consistent with the changes we describe here. The collective experience of this limited number of patients so far would suggest that complete 


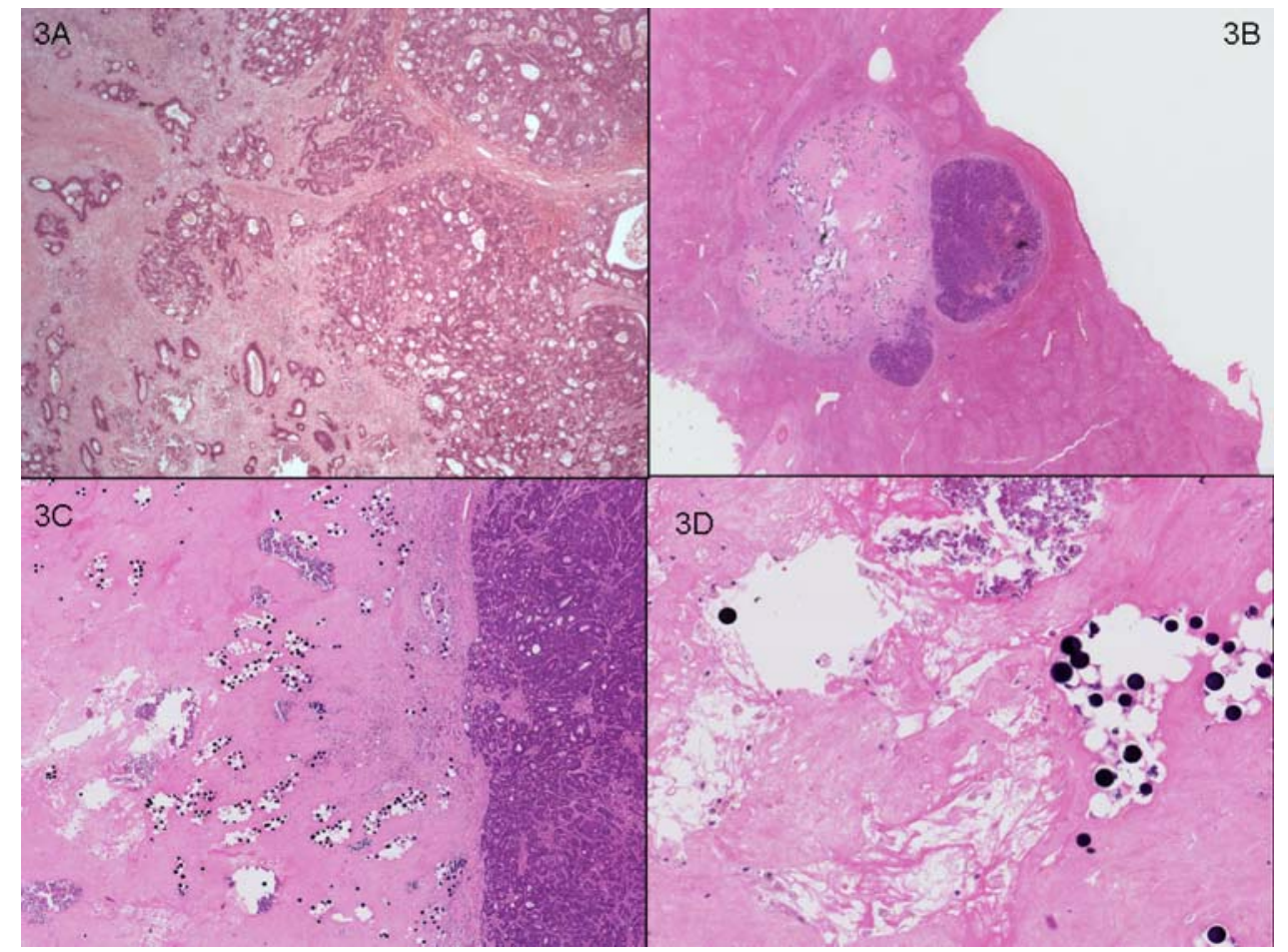

Figure 3 Case 1. (A) Representative section of lesion $1(20 x)$ in segment IV, $40 \mathrm{~mm}$ in size, showing minimal tumour response (70\% viable tumour cells) and few scattered foci of calcification. (B) Representative section of lesion 2 in left hepatectomy, 12 mm, with partial tumour response (30\% viable tumour cells seen in entire lesion sampled). (C) Residual well demarcated metastatic colorectal adenocarcinoma next to responsive area showing fibrosis $(20 x)$, calcification and paucicellular fibrinous exudate adjacent to microspheres (D, 100x).

pathological response can be achieved and that SIRT is potentially an effective treatment option for patients with liver metastases from CRC.
SIRT has also been termed 'radio-embolisation' by an international consortium ${ }^{23}$ and there is current debate as to whether it acts primarily via arterially directed delivery of high dose

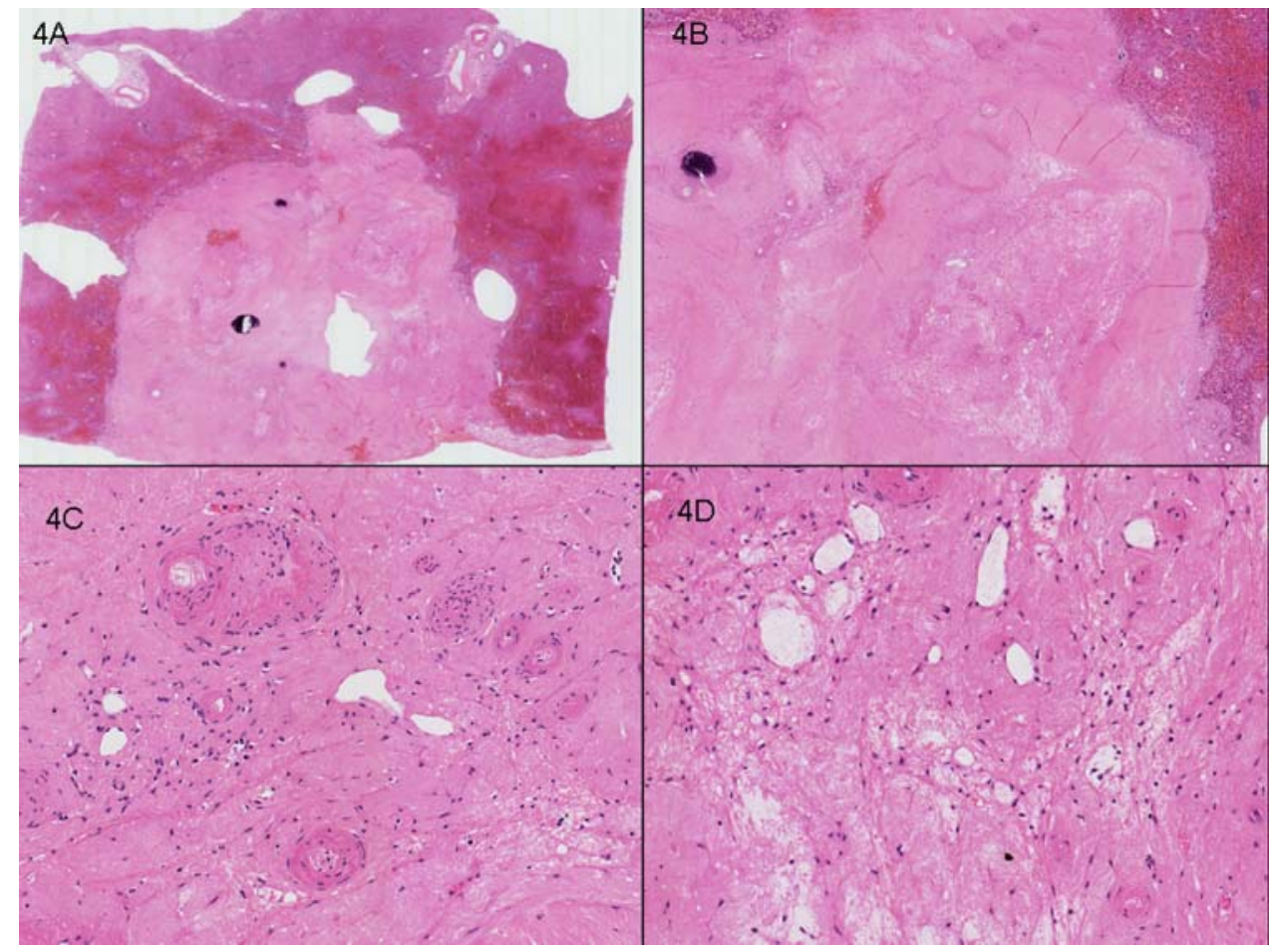

Figure 4 Case 2. Right hepatectomy with two synchronous tumours. (A) Representative section of lesion 1, $15 \mathrm{~mm}$, showing complete pathological response. (B) No viable tumour cells were seen and the 'intratumoural' zone contains marked fibrosis, calcification and paucicellular fibrinous exudate. (C) Ectatic vessels with the larger calibre vessels showing hyalinisation and intimal thickening. (D) Gapping ectatic vessels in association with loose fibrinous exudate and foamy histiocytes. 


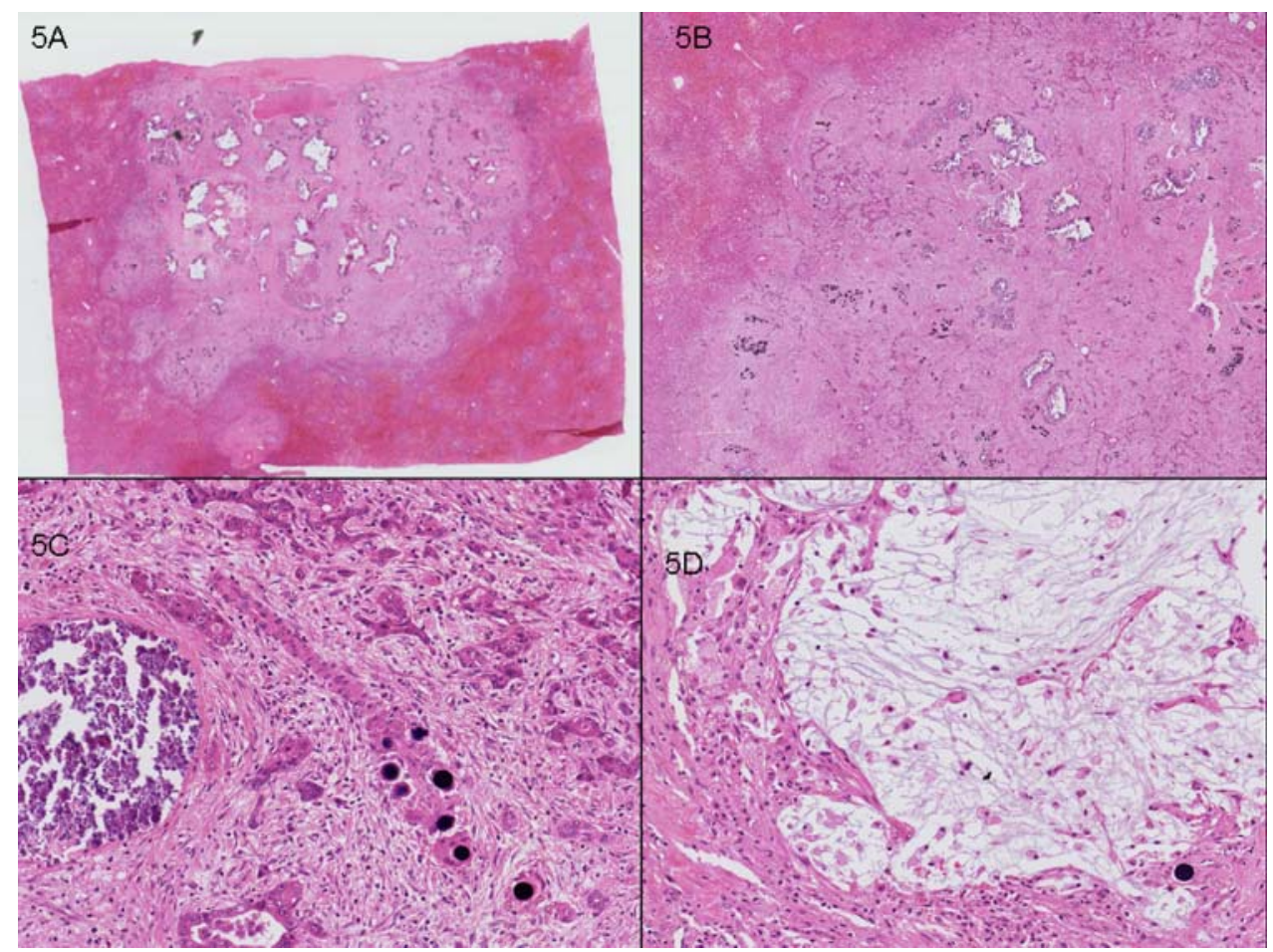

Figure 5 Case 2. Right hepatectomy with two synchronous tumours. (A) Representative section of lesion 2, $10 \mathrm{~mm}$, showing good partial pathological response. (B) $(10 x)$ and (C) $(100 x)$. Residual tumour (20\% viable tumour cells), fibrosis and calcification are seen. (D) Mucinous change and foamy histiocytes $(100 \times)$ are identified.

radiotherapy in and around the vascular tumour bed, or by micro-arterial embolisation, cutting off the blood supply to malignancies. The microspheres can limit the blood supply to tumours by being physically lodged in the tumour vasculature. On the other hand, the path length for the $\beta$-radiation emitted from the yttrium-90 is several $\mathrm{mm}$ in human tissue. ${ }^{3}$ In our

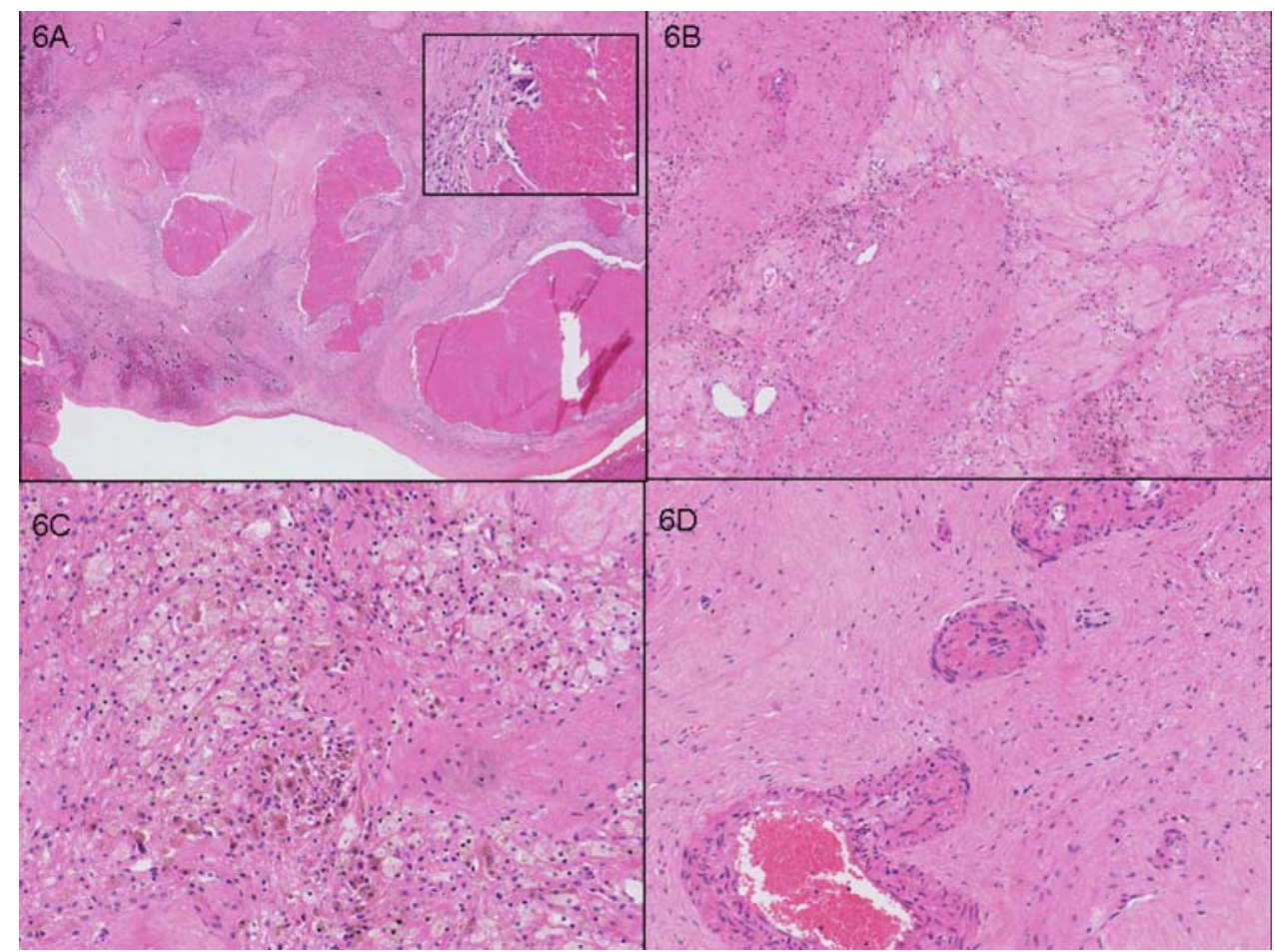

Figure 6 Case 3. Right hepatectomy with tumour nodule $40 \mathrm{~mm}$ showing good partial pathological response (30\% viable tumour cells). (A) Tumour necrosis $(10 \times)$ with inset $(200 x)$, to demonstrate the lack of inflammatory cells such as polymorphs within necrotic debris. (B) Fibrosis and ectatic vessels. (C) Foamy histiocytes in association with haemosiderin pigment. (D) Larger calibre vessels showing tortuosity and intimal alteration. 
Table 1 Summary of histological findings in liver resection specimens after SIRT for metastatic colorectal carcinoma

\begin{tabular}{|c|c|c|c|c|c|}
\hline & No. of patients & $\begin{array}{l}\text { Type of metastatic } \\
\text { tumour }\end{array}$ & No. of tumour deposits & $\begin{array}{l}\text { Complete } \\
\text { pathological } \\
\text { response }\end{array}$ & $\begin{array}{l}\text { Summary of histology } \\
\text { findings in mCRC cases }\end{array}$ \\
\hline Our study & 3 & $\mathrm{mCRC}$ & 5 & 1 & $\begin{array}{l}\text { Microspheres } \\
\text { Tumour bed } \\
\text { Tumour necrosis } \\
\text { Stromal fibrinous exudate } \\
\text { Paucicellular inflammatory } \\
\text { response } \\
\text { Mucin } \\
\text { Foamy histiocytes } \\
\text { Calcification } \\
\text { Fibrosis } \\
\text { Ectatic vessels and vascular } \\
\text { intimal alteration } \\
\text { Background } \\
\text { Tumour mass effect } \\
\text { Steatosis } \\
\text { VOD }\end{array}$ \\
\hline $\begin{array}{l}\text { Hadaki } \\
\text { et } a l^{22}\end{array}$ & 1 & $\mathrm{mCRC}$ & 2 & 2 & $\begin{array}{l}\text { Microspheres } \\
\text { Tumour bed } \\
\text { Fibrosis } \\
\text { Mucin }\end{array}$ \\
\hline $\begin{array}{l}\text { Whitney } \\
\text { et } a l^{15}\end{array}$ & $\begin{array}{l}4 \text { ( } 4 \text { of } 44 \text { with } \\
\text { postoperative pathology) }\end{array}$ & $\begin{array}{l}1 \mathrm{mCRC} \\
1 \text { oesophageal } \\
2 \text { cholangiocarcinoma }\end{array}$ & $\begin{array}{l}\text { Not specified in pathology description of } \\
\text { specimens (a total of } 9 \text { target lesions) }\end{array}$ & None & $\begin{array}{l}\text { Microspheres (not specified) } \\
\text { Tumour necrosis }\end{array}$ \\
\hline
\end{tabular}

mCRC, metastatic colorectal cancer; SIRT, selective internal radiation therapy; VOD, veno-occlusive disease.

series, with the time from SIRT to surgery ranging from 4 to 9 months, the final resected specimens showed predominantly histological evidence of a local radiotherapy effect such as fibrosis, ectatic vessels, vascular changes and fibrinous exudate. The lack of cellular inflammatory cell infiltrate, such as granulocytes, is a useful feature in distinguishing these radiation related changes from histopathological changes induced by embolisation or by chemotherapy. ${ }^{16}$ Our findings support the hypothesis that the main mechanism of action of this form of therapy is via arterially directed delivery of high dose radiotherapy in and around the vascular tumour bed.

\section{Take-home messages}

- Meticulous anatomical observation can lead to the development of effective new ways to treat cancer.

- The afferent blood supply to malignant fibrovascular stroma originates from the hepatic artery rather than the portal vein.

- Arterially directed therapies for primary and secondary liver malignancies are in routine clinical use, such as trans-arterial chemo-embolisation and selective internal radiotherapy (SIRT).

- We present clinical evidence that the principal mechanism of action of SIRT appears to be via arterially directed delivery of high dose radiotherapy in and around the vascular tumour bed, rather than via micro-arterial embolisation.

Contributors All authors contributed to the analysis, interpretation of data and writing of the paper.

Funding NIHR Biomedical Research Centre Oxford: funding of SIRT treatment and clinician time. RAS is funded by the NIHR Biomedical Research Centre Oxford, the
Higher Education Funding Council for England, the Bobby Moore Fund of Cancer Research UK and the UK Medical Research Council.

Competing interests RAS has received research funding from Sirtex Medical Ltd. Patient consent Obtained.

Ethics approval Clinical audit: individual consent obtained.

Provenance and peer review Not commissioned; externally peer reviewed.

Open Access This is an Open Access article distributed in accordance with the Creative Commons Attribution Non Commercial (CC BY-NC 3.0) license, which permits others to distribute, remix, adapt, build upon this work non-commercially, and license their derivative works on different terms, provided the original work is properly cited and the use is non-commercial. See: http://creativecommons.org/licenses/by-nc/3.0/

\section{REFERENCES}

1 Cabibbo G, Latteri F, Antonucci M, et al. Multimodal approaches to the treatment of hepatocellular carcinoma. Nat Clin Pract Gastroenterol Hepatol 2009;6:159-69.

2 Kerr D, McArdle C, Ledermann J, et al. Intrahepatic arterial versus intravenous fluorouracil and folinic acid for colorectal cancer liver metastases: a multicentre randomised trial. Lancet 2003;361:368-73.

3 Nicolay NH, Berry DP, Sharma RA. Liver metastases from colorectal cancer: radioembolization with systemic therapy. Nature Rev Clin Oncol 2009;6: 687-97.

4 Boerhaave H. Academical lectures on the theory of physic being. A genuine translation of his institutes and explanatory comment. London: W. Innys, 1774

5 Willis RA. Mitosis in the hepatic metastases of malignant tumours. J Path \& Bact 1932;35:11.

6 Wright RD. The blood supply of newly developed epithelial tissue in the liver. J Path \& Bact 1937:45:405-14.

7 Breedis C, Young G. The blood supply of neoplasms in the liver. Am J Pathol 1954;30:969-77.

8 Sullivan R, Miller $E$, Sikes M. Antimetabolite-metabolite combination cancer chemotherapy. Cancer 1959;12:1248-62.

9 Brennan M, Talley E, Drake E, et al. 5-fluorouracil treatment of liver metastases by continuous hepatic artery infusion via Cournand catheter. Ann Surgery 1963;158:405-19.

10 Doyon D, Mouzon A, Jourde A, et al. Hepatic, arterial embolization in patients with malignant liver tumours (author's transl from French). Ann Radiol (Paris) 1974; 17:593-603.

11 Nakakuma K, Tashiro S, Hiraoka T, et al. Studies on anticancer treatment with an oily anticancer drug injected into the ligated feeding hepatic artery for liver cancer. Cancer 1983:52:2193-200. 
12 Sharma RA, Wasan HS, Love SB, et al. on behalf of the FOXFIRE trial management group. FOXFIRE: a Phase III Clinical Trial of Chemo-radio-embolisation as first-line treatment of liver metastases in patients with colorectal cancer. Clin Oncol 2008:20:261-3.

13 Sharma RA, Van Hazel G, Morgan B, et al. Radioembolization of liver metastases from colorectal cancer using yttrium-90 microspheres with concomitant systemic oxaliplatin, fluorouracil, and leucovorin chemotherapy. I Clin Oncol 2007;25:1099-106.

14 Van den Eynde M, Flamen P, Nakadi IE, et al. Inducing resectability of chemotherapy refractory colorectal liver metastasis by radioemblization with yttrium-90 microspheres. Clin Nuc Med 2008;33:697-8.

15 Whitney R, Tatum C, Hahl M, et al. Safety of hepatic resection in metastastic disease to the liver after yttrium-90 therapy. J Surg Res 2011;166:236-40.

16 Fajardo LF, Berthrong M, Anderson RE. Radiation pathology. New York: Oxford University Press USA, 2001: 153-63.

17 Rubbia-Brandt L, Audard V, Sartoretti P. Severe hepatic sinusoidal obstruction associated with oxaliplatin-based chemotherapy in patients with metastatic colorectal cancer. Ann Oncol 2004;15:460-6.
18 Guan S, Zhao W, Zhou K, et al. Assessment of hemodynamics in precancerous lesion of hepatocellular carcinoma: Evaluation with MR perfusion. World J Gastroenterol 2007;13:1182-6.

19 Dezso K, Bugyik E, Papp V, et al. Development of arterial blood supply in experimental liver metastases. Am J Pathol 2009:175:835-43.

20 Kudo M, Tochio $\mathrm{H}$. Intranodular blood supply correlates well with biological malignancy grade determined by tumor growth rate in pathologically proven hepatocellular carcinoma. Oncology 2008;75(Suppl 1):55-64.

21 Tsushima Y, Funabasama S, Aoki J, et al. Quantitative perfusion map of malignant liver tumors, created from dynamic computed tomography data. Acad Radiol 2004;11:215-23.

22 Hadaki M, Praseedom R, Brais R, et al. Selective internal radiation therapy with 90Y-SIR-Spheres microspheres for non-resectable colorectal metastases in the liver. BMJ Case report 2011. pii: bcr0120113793. doi: 10.1136/bcr.01.2011.3793.

23 Kennedy A, Nag S, Salem R, et al. Recommendations for radioembolization of hepatic malignancies using Yttrium-90 (Y90) microsphere brachytherapy: a consensus panel report from the Radioembolization Brachytherapy Oncology Consortium (REBOC). Int I Rad Oncol Biol Phys 2007:68:13-23. 